\title{
Peer review of teaching in Australian higher education: a systematic review
}

\section{Alexandra L. Johnston , Chi Baik \& Andrea Chester}

To cite this article: Alexandra L. Johnston , Chi Baik \& Andrea Chester (2020): Peer review of teaching in Australian higher education: a systematic review, Higher Education Research \& Development, DOI: 10.1080/07294360.2020.1845124

To link to this article: https://doi.org/10.1080/07294360.2020.1845124

曲 Published online: 18 Nov 2020.

Submit your article to this journal $\longleftarrow$

Џll Article views: 227

Q View related articles $\asymp$

View Crossmark data $₫$ 


\title{
Peer review of teaching in Australian higher education: a systematic review
}

\author{
Alexandra L. Johnston (D) ${ }^{\mathrm{a}, \mathrm{b}}$, Chi Baik (D) ${ }^{\mathrm{c}}$ and Andrea Chester (1D) \\ ${ }^{a}$ Williams Centre for Learning Advancement, University of Melbourne, Melbourne, Australia; ' 5 School of \\ Education, RMIT University, Melbourne, Australia; 'Centre for the Study of Higher Education, University of \\ Melbourne, Melbourne, Australia
}

\begin{abstract}
Over recent decades, peer review of teaching has become an important mechanism for improving the quality of teaching in higher education. While there is considerable international research on peer review of teaching outcomes, these are not widely reported within Australian universities. This paper reports on a systematic review of published studies examining peer review of teaching characteristics that contribute to teaching development in Australian higher education. Following a search of peer reviewed literature published over three decades, 19 studies were included in the qualitative synthesis. A thematic synthesis revealed teaching development outcomes gained through peer review of teaching span factors at organisational ( $N$ $=16)$, program $(N=13)$ and individual $(N=4)$ levels. Organisational factors included disciplinary context, program sustainability, collegiality and leadership. Program factors included framework, program design, basis of participation, observation, feedback and reflective practice. Factors at the individual level included prior experience and participants' perceived development requirements. In addition to reporting on teaching development outcomes, some studies reported on enhanced student learning outcomes $(N=5)$. Improved reporting of program design in addition to validated tools to assess outcomes are required to better understand how peer review of teaching supports teaching development. The growth of peer review of teaching within Australian higher education presents an important opportunity to advance our understanding of practices influencing academic teaching development.
\end{abstract}

\section{ARTICLE HISTORY}

Received 29 July 2019

Accepted 1 October 2020

\section{KEYWORDS}

Peer review of teaching; peer observation of teaching; academic teaching development; higher education; quality of teaching

\section{Introduction}

Over recent decades, peer review of teaching (PRT) has become an important mechanism for improving the quality of teaching in higher education (HE). While there is considerable international research on PRT outcomes (Lomas \& Nicholls, 2005; Servilio et al., 2017; Yurtseven \& Altun, 2018), these are not widely reported within Australian universities (Burrows et al., 2011; Lomas \& Kinchin 2006). Efforts to undertake PRT in the Australian tertiary sector have generally been informal small-scale projects, where results are 
often not published (Harris et al., 2008). This systematic review aims to further our understanding of factors within PRT that contribute to teaching development within the underexplored context of Australian HE.

While the term itself is contested, for this study PRT is defined as a process where teaching academics provide feedback on one another's practice to improve quality of teaching (Harris et al., 2008). Developments within the HE sector over recent decades have contributed to an increased focus on teaching quality, and PRT has been proposed by numerous scholars as both an effective approach to academic teaching development and an important factor in improving teaching quality outcomes (Barnard et al., 2011; Bell, 2001; Chester, 2012; Harris et al., 2008). In other words, PRT functions both as a mechanism for enhancing teaching quality and a measure to indicate quality of teaching. The outcomes of PRT may contribute to formal evaluation and recognition of teaching performance (Harris et al., 2008). Evaluating academic teaching quality is important for enhancing teaching and learning outcomes and realising organisational strategic objectives to improve teaching (Baik \& Blasioli, 2018). PRT also offers an alternative addition to student evaluations as the current prevailing measure of teaching quality within $\mathrm{HE}$.

Internationally, PRT is recognised as an important component of academic teaching scholarship, akin to the peer review of research as an established approach necessary to academic writing scholarship (Boyer, 1990; Quinlan \& Akerlind, 2000). However, while PRT has been widely used across other education sectors since the 1950s in Australia (Bell, 2001), it is generally not found in Australian HE policy (Barnard et al., 2015). Several authors (e.g., Barnard et al., 2011; Lomas \& Nicholls, 2005) have argued that to maintain Australia's competitive position within the global quality agenda, it is imperative that institutions leverage emerging PRT initiatives to further support the development of $\mathrm{HE}$ at the national, organisational and disciplinary levels.

Developing research supports the positive relationship between targeted PRT programs for university educators and enhanced teaching development outcomes (Hammersley-Fletcher \& Orsmond, 2004; Martin \& Double, 1998; Shortland, 2010). At an individual level, benefits for teaching academics include development of reflective practice, enhanced collegiate relationships and increased teaching effectiveness (Bowen, 2009; Suri \& Clarke, 2009; White et al., 2013). At an institutional level, PRT processes can promote a shift in teaching approach from teacher-focused to student-focused (Baik et al., 2018) improved student leaning outcomes (Marchant et al., 2018) and a focus on teaching quality (Bell \& Thomson, 2018).

However, initial analysis of PRT program structure reveals important differences in program efficacy. This may be due to various factors including how observations are conducted, whether participants have a degree of control within the process, and the intended use of data related to outcomes (McMahon et al., 2007). Other factors may be due to a peer review process embedded within formal professional development mechanisms, such as the Graduate Certificate in University Teaching (Bell, 2001), or voluntary communities of practice (Barnard et al., 2011). The use of PRT can be embedded within an institution's performance review process (Hammersley-Fletcher \& Orsmond, 2004), or as an opt-in professional development exercise (Kell \& Annetts, 2009). Some programs enable participants to select their peer reviewer (Bell \& Mladenovic, 2008) or an educational developer (Bell, 2001). Opt-in program designs often feature reciprocal relationships with both partners involved in observing each other's teaching 
(Donnelly, 2007). A training component in teaching scholarship is sometimes embedded within the process, however it is not always evident whether training is mandated or even provided (Shortland, 2004).

These differing approaches may ultimately influence both teaching development and teaching quality outcomes (Gosling, 2013). Recent scholarly arguments suggest that PRT evaluative mechanisms can contribute to variances in program efficacy. These mechanisms may necessitate a judgemental and value-laden approach that assumes unequal power between the reviewer and reviewee (Grainger et al., 2015). Consequently, scholars have proposed a PRT model that promotes collegiate learning related to academic teaching development (Gosling \& O'Connor, 2006). Initial findings based on this model may have important implications for the development of PRT. For example, where collegiate PRT partnerships are supported through institutional policy and flexible leadership (Bell \& Cooper, 2013), learning about teaching is optimised and institutional cross-fertilisation of teaching quality is fostered (White et al., 2013).

Subsequently, scholars have called for further examination of teaching academics' experiences of program factors that contribute to teaching development (Georgiou et al., 2018; Grainger et al., 2015). Understanding which levers account for improving teaching development and teaching quality outcomes can assist in forming a case for sectorial investment in evidence-based PRT programs. This systematic review asks What factors within PRT contribute to teaching development in Australian HE? Before outlining the methods used to conduct the review, it is important to clarify terminology used in the literature.

\section{Peer review of teaching terminology}

A range of terms is used to describe PRT. Table 1 summarises the models used to describe PRT. The conflation of terminology suggests the models are not mutually exclusive. For example, while there appears to be little difference between the elements defining the evaluative and the development models, important differences may be found in both the function of the observer's role and the objective of the PRT process. (i.e., authoritative versus expert diagnosis).

The differing terminology used to describe PRT is discussed extensively within the literature. For example, Alabi and Weare (2014) outlined numerous terms used to describe

Table 1. Models used to describe peer review of teaching.

\begin{tabular}{|c|c|c|}
\hline Model & Elements & Objective \\
\hline Formative & $\begin{array}{l}\text { Observation, critical reflection, appraisal, collegial } \\
\text { practice exchange and improvement strategies }\end{array}$ & $\begin{array}{l}\text { Continuous professional development and } \\
\text { improved teaching quality }\end{array}$ \\
\hline Diagnostic & Reviewed by experienced academic & $\begin{array}{l}\text { Identifies and addresses teaching practice } \\
\text { issues }\end{array}$ \\
\hline Summative & $\begin{array}{l}\text { Reviewed by experienced academic or educational } \\
\text { developer }\end{array}$ & Academic promotion \\
\hline Evaluative & $\begin{array}{l}\text { Peer observation by experienced academic or } \\
\text { management }\end{array}$ & $\begin{array}{l}\text { Authoritative diagnosis of perceptions of } \\
\text { teaching }\end{array}$ \\
\hline Developmental & Peer observation by educational developer & $\begin{array}{l}\text { Expert diagnosis of perceptions of } \\
\text { teaching }\end{array}$ \\
\hline
\end{tabular}

Note: Adapted from Gosling (2002) and Lomas and Kinchin (2006). 
PRT across 17 studies, including collegial observation, peer appraisal, peer coaching, peer evaluation, peer feedback, peer observation and peer review. Additionally, ambiguity of PRT terminology may be an indicator of a dearth of PRT-related literature. Towards countering this, Gosling (2002, p. 5) contends, 'Teaching staff need to develop a language to discuss teaching and adopt a more scholarly approach to discussion of it through a peer review model.' More recent scholarship conceives PRT as a tool for developing a shared organisational language between learning and teaching scholars and discipline experts (Klopper \& Drew, 2015).

\section{The study}

The aim of this review is to identify factors in PRT programs that are effective in improving teaching development within Australian HE.

\section{Method}

A systematic approach to the literature review was informed by Creswell's (2002) fivestep process. This included identifying key terms for use in the literature search, locating literature within relevant databases, determining the relevance of results, further refining these using inclusion and exclusion criteria, and organising the literature selected. The stages of the literature review process are illustrated in Figure 1.

\section{Key terms and databases}

A comprehensive online investigation was conducted of peer reviewed literature published from January 1990 until May 2020. Databases accessed via EBSCO were determined based on their inclusion of a diversity of educational research journals. These databases included Academic Research Complete, Education Research Complete, Educational Administration Abstracts, Education Resources Information Center, A+ Education (Informit) and Google Scholar. The selection of search term combinations involved an iterative process.

The first iteration included the terms: '("peer review") AND teach* AND universit*'.

Due to the limited universal use of the term 'university' within the article types, the search was expanded to: 'peer review' AND teach* AND universit* AND 'higher education'. The search terms were further developed to include 'college' and 'tertiary education' to locate relevant studies within the higher education sector. The search terms were modified to broaden the criteria beyond the limitations of 'peer review' to include 'peer observation': '(lecturing OR teaching) AND ('higher education' OR universit* OR college ${ }^{\star}$ OR 'tertiary education') AND ('peer-review' OR 'peer review' OR 'peer observation') AND Australia*'. The final combination involved the terms: '(lecturing OR teaching) AND ('higher education' OR universit ${ }^{\star}$ OR college ${ }^{\star}$ OR 'tertiary education') AND ('peer review of teaching' OR 'peer observation of teaching' OR 'peer evaluation of teaching' OR 'peer feedback on teaching' OR 'peer partner') AND Australia*' 


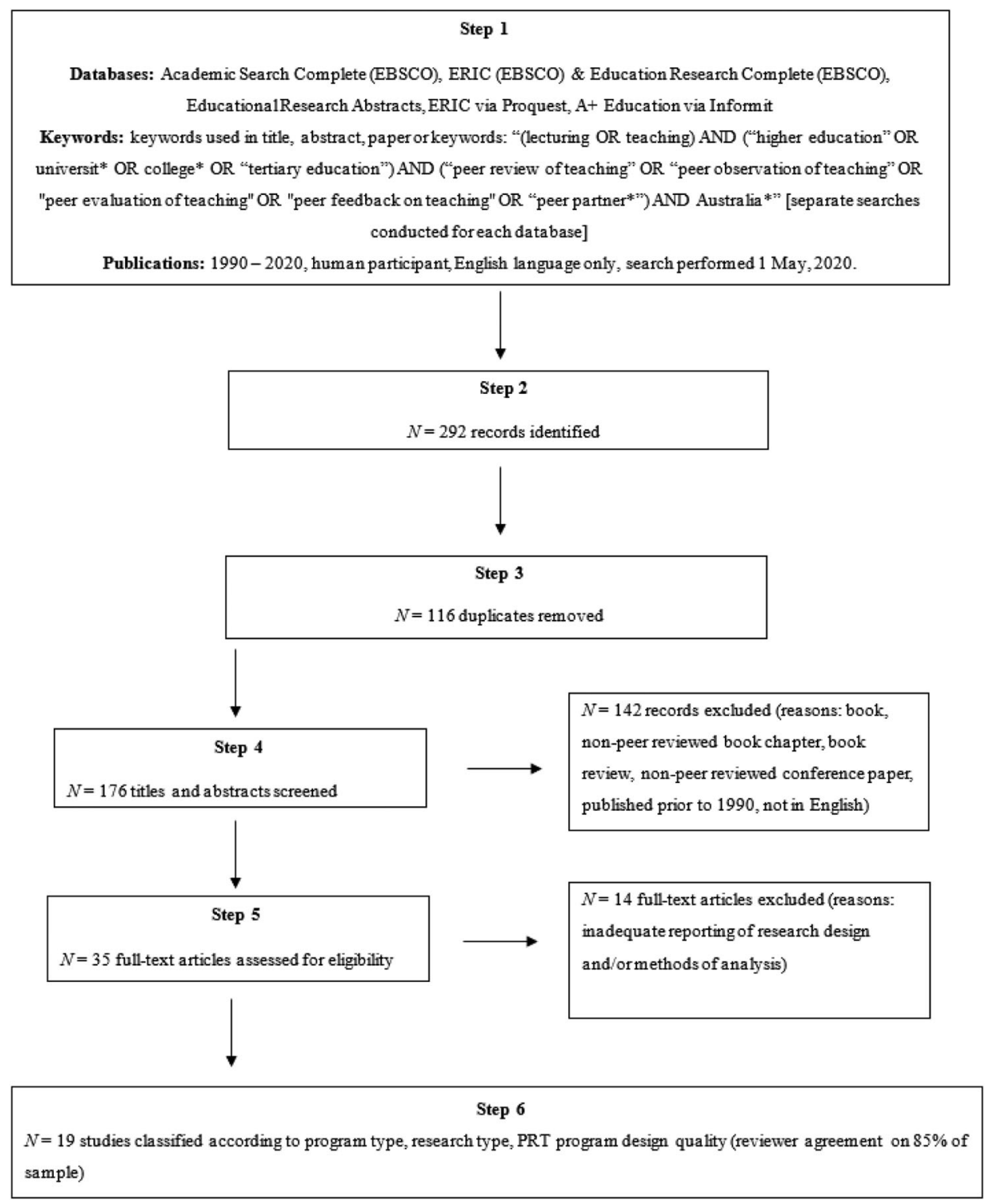

Figure 1. Stages of the literature selection process.

\section{Selection procedure}

As illustrated in Figure 1, a total of 292 records were identified through the database search. After duplicates were removed, 176 titles and abstracts were screened. After screening according to inclusion and exclusion criteria (see Table 2), 34 full-text articles were assessed for eligibility. Of these, 19 studies were identified for inclusion in the qualitative synthesis (see Table 2). To ensure articles with acceptable quality were selected and that potentially suitable articles were not lost due to reviewer bias, reviewers conducted independent reviews of the papers according to predetermined quality checks. Disagreement about inclusion of studies was resolved through discussion between all researchers. 
Table 2. Articles included in the review.

\begin{tabular}{lllll}
\hline Paper & \multicolumn{1}{c}{ Authors } & \multicolumn{1}{c}{ Participants $(N)$} & \multicolumn{1}{c}{ Research Design $^{\text {a }}$} & \multicolumn{1}{c}{ Method $^{\text {b }}$} \\
\hline 1 & Atkinson and Bolt (2010) & $N=10$ Academics & Qual & AR, O, QS, WF \\
2 & Barnard et al. (2011) & $N=298$ Academics & Mixed & AR, QS, S \\
3 & Bell (2001) & $N=28$ Lecturers & Qual & O, R \\
4 & Bell and Cooper (2013) & $N=12$ Engineering academics & Mixed & CS, QS, O, S, I, W \\
5 & Bell and Mladenovic (2008) & $N=32$ Business Tutors & Mixed & O, R, S, FG, I \\
6 & Bell and Mladenovic (2015) & $N=144$ Business Tutors & Mixed & O, R, S, FG, I \\
7 & Bennett et al. (2012) & $N=20$ Sciences academics & Quant & S \\
8 & Carbone (2011) & $N=6$ STEM academics & Mixed & FG, S, SLO \\
9 & Chester (2012) & $N=18$ Academics & Mixed & S, QS, FG \\
10 & Cresswell et al. (2015) & $N=4$ Academics & Mixed & QS, S, SLO \\
11 & Georgiou et al. (2018) & $N=29$ STEM academics & Mixed & FN, W, S, QS \\
12 & Klopper and Drew (2015) & $N=124$ Academics & Qual & AR, QS, R, SLO \\
13 & Klopper et al. (2015) & $N=125$ Academics & Qual & O, R, SLO \\
14 & O'Keefe et al. (2009) & $N=20$ Academics & Qual & CS, O, SLO \\
15 & Venema et al. (2015) & $N=2$ Education academics & Qual & I \\
16 & Wingrove et al. (2015) & $N=10$ University leaders & Qual & I \\
17 & Wingrove et al. (2017) & $N=18$ University leaders & Qual & O, D \\
18 & Woodman and Parappilly (2015) & $N=2$ Early career lecturers & Qual & AR, F, R, SLO \\
19 & Wright and Main (2015) & $N=2$ Academics & Qual & Q \\
\hline
\end{tabular}

Note: a. Mixed: mixed methods; Qual: qualitative methods; Quan: quantitative methods; b. D: documents; CS: Case Study; FG: focus groups; FN: field notes; I: interviews; N: narratives; O: observations; QS: qualitative survey; R: reflections; S: survey; SLO: student learning outcomes; T: training; WF: written feedback; W: workshop.

Suri and Clarke's (2009) methodologically inclusive research synthesis (MIRS) was used as this approach purposefully highlights research contributions from interpretive, participatory, and critical perspectives. The MIRS includes six phases of considerations relevant to the present quality research synthesis, identified in Table 3 . Within the MIRS framework, evidence, methodological perspectives, and techniques employed in knowledge construction that is qualitative, quantitative, or a combination of both are recognised and assessed for inclusion. Each of the six MIRS phases were developed as a key question in order to draw out the relevant information from the studies, outlined in Table 3.

The 19 articles included 10 qualitative, 8 mixed-method and 1 quantitative study. Qualitative study sample sizes ranged from 2 to 125 participants. Sample sizes of the mixed-method studies varied from 6 to 298, while the quantitative study included a sample size of 20. Of the 19 articles, 18 studies were conducted within Australia, and 1 study included Australian and UK participants. The scale of the studies extended from

Table 3. Framework and key questions informing eligibility criteria.

\begin{tabular}{|c|c|}
\hline MIRS framework phases & Key question used \\
\hline $\begin{array}{l}\text { 1. Drawing from pertinent philosophical and } \\
\text { theoretical discussions }\end{array}$ & 1. Is there a clear articulation of study design? \\
\hline 2. Identifying an appropriate purpose & $\begin{array}{l}\text { 2. Is a clear alignment made between the aim, methods, research } \\
\text { question and conclusion? }\end{array}$ \\
\hline 3. Searching for relevant evidence & 3. Does the methodology enable inclusion of relevant evidence? \\
\hline $\begin{array}{l}\text { 4. Evaluating, interpreting, and distilling } \\
\text { evidence }\end{array}$ & $\begin{array}{l}\text { 4. Is an analysis and synthesis of relevant evidence included within the } \\
\text { methods used? }\end{array}$ \\
\hline 5. Constructing connected understandings & $\begin{array}{l}\text { 5. Are the results of the analysis and synthesis connected with the } \\
\text { research question and made clear within the conclusion? }\end{array}$ \\
\hline 6. Communicating with an audience & $\begin{array}{l}\text { 6. Is the paper communicated with the intended audience through a } \\
\text { publication recognised for quality? }\end{array}$ \\
\hline
\end{tabular}

Note: Based on Suri and Clarke's (2009) methodologically inclusive research synthesis (MIRS). 
single discipline to whole-of-institution. Participants included sessional tutors, teaching and research academics and university leaders.

After extracting the results from the articles that met our quality criteria, the results and discussion sections were analysed using a thematic synthesis (see Thomas et al., 2012). Through inductive coding, themes were identified and used to compare articles according to findings regarding teaching development, and success-related factors for PRT programs. The following section outlines the findings in relation to the following three themes: organisational factors, program factors and individual factors. These were discussed within the literature as factors influencing teaching development.

\section{Results}

Results in relation to the research question are presented thematically and discussed in this section. Table 4 summarises these themes and their supporting studies.

\section{Organisational factors}

Organisational factors are defined as attributes within organisations that support teaching development to occur, such as culture, structure and policy. The organisation determines how the program will be led within various disciplinary cultures and contextually specific requirements.

Organisational factors were presented under the themes of context, sustainability and collegiality within seventeen $(89 \%)$ articles reviewed. The majority specified collegiate organisational contexts were important to academic teaching development in addition to expansion of collegiate networks. The importance of collegiate contexts for early career academics' development was identified. Personalised, discipline-specific approaches had a stronger alignment with academic teaching development than generic large-scale policy-driven organisational initiatives.

Program sustainability was a factor that impacted program efficacy. A distributed leadership approach was a means of positioning program responsibility at a localised faculty level, with the aim of implementing scalable, lasting teaching development. Training and

Table 4. Thematic overview of studies.

\begin{tabular}{|c|c|c|c|}
\hline Theme & Sub-Themes & Relevant studies $^{a}$ & Frequency \\
\hline \multirow{5}{*}{ Organisational Factors } & & & 17 (89\%) \\
\hline & Context & $7,8,9,11,19$ & 5 \\
\hline & Sustainability & $1,4,5,9,12,16,17,19$ & 8 \\
\hline & Collegiality & $2,3,4,7,9,10,11,13,14,17,18$ & 11 \\
\hline & Leadership & $4,16,17$ & 3 \\
\hline \multirow{6}{*}{ Program Factors } & & & $13(68 \%)$ \\
\hline & Framework and Purpose & $1,3,4,9,10,11,12,19$ & 7 \\
\hline & Program Design & $3,4,11,14$ & 4 \\
\hline & Participation Basis & $1,3,4,5,9,10,14$ & 7 \\
\hline & Feedback and Observation & $1,3,4,5,6,8,10,11,12,13,14,19$ & 12 \\
\hline & Reflective Practice & $3,5,6,13$ & 4 \\
\hline \multirow[t]{3}{*}{ Individual Factors } & & & $4(21 \%)$ \\
\hline & Teaching Experience & 11,18 & 2 \\
\hline & Teacher Perceptions & 9,10 & 2 \\
\hline Total & & & 11 sub-themes (100\%) \\
\hline
\end{tabular}

${ }^{a}$ Numbers listed under 'Relevant studies' correspond to the numbers identifying studies in Table 2. 
ongoing mentoring in addition to voluntary, cross-disciplinary partnerships contributed to program sustainability.

\section{Program factors}

Identified as the structure of the overall program and design of various components, program factors are central to determining program engagement and achieving successful outcomes.

Thirteen articles (68\%) presented structural program components including purpose, framework (used synonymously with 'model'), design, basis of participation, reflective practice, feedback and observation. Most frequently reported components were feedback and observation, discussed by twelve authors. Five of these described the positive role of observation of peers and formative collegiate feedback. The role of an educational developer or expert reviewer in providing effective feedback was reported as important, while inclusion of group feedback processes afforded participants the opportunity to benefit from others' knowledge and experience.

Seven studies discussed PRT purpose and framework as important attributes. Higher motivation levels were evident where teaching staff engaged for formative incentives rather than summative rewards. Clarity of aim and scope in addition to rigorous use of peer observation data within a systematic teaching quality framework were reported as key framework features. Four articles reported reflective practice promoted collegial collaboration, particularly where participants were supported to critically reflect and implement change.

\section{Individual factors}

Individual factors are defined as individuals' unique, inherent characteristics that may influence their experience of PRT. Four (21\%) of the articles reviewed referred to individual factors, most notably prior teaching experience and participants' perceived development requirements. A barrier to program involvement was participants' perceptions about program benefits and limitations relative to their development needs. Within STEM disciplines authors identified experienced reviewer feedback was important, while early career science teaching academics' engagement in PRT positively shaped teaching pedagogy and attitudes to teaching, without the involvement of experienced teaching faculty. Participants' perceptions of disciplinary differences were reported to have influenced evaluations of their peers' teaching development within cross-disciplinary partnerships.

\section{Discussion}

What type of PRT program contributes to teaching development, and in what circumstances?

PRT involves a complex array of factors, contributing to a range of teaching development related outcomes at the organisational, program and individual levels. This synthesis indicates varying degrees of agreement between studies at each of these levels. 
At the organisational level, contextual factors relating to discipline requirements were key to promoting teaching development. The review reveals the debate over the importance of having a discipline-specific reviewer. Several authors advocated the observer should be a peer from the same discipline, a senior academic administrator or an educational developer (Atkinson \& Bolt, 2010; Bell, 2001; Georgiou et al., 2018). Others argued a cross-disciplinary perspective supports a focus on underlying pedagogy (Chester, 2012), removes learning and teaching silos, connects academics from different disciplines and leads to improvements in outcomes for both students and teachers (Venema et al., 2015). The broader literature recommends cross-disciplinary development activities where STEM, nursing or business teaching is concerned (Viskovic, 2006).

Leadership support from faculty heads was found to be essential, as was program alignment within university processes. Failure to communicate program value, prioritise teaching outputs and adequately resource program initiatives had implications for participant buy-in (Bell, 2001; Bennett et al., 2012). Leaders participating as equal partners, modelling program requirements was critical (Bell \& Cooper, 2013) as was a distributive leadership approach (Wingrove et al., 2015; Wingrove et al., 2017), which is similarly discussed in the wider literature (Nash et al., 2014). Value placed on PRT at the organisational level was positively related to leadership engagement and successful program application (Carroll \& O'Loughlin, 2014; Lomas \& Nicholls, 2005), however others reported department heads were not necessarily the determining factor influencing participant engagement, despite the important role of these leaders within the program (Chamberlain et al., 2011). The broader literature points to open communication from leaders (Brown \& Ward-Griffin, 1994) and acknowledgement of pedagogical needs particular to the faculty culture (Martsolf et al., 1998).

At the program level, whether staff participated in formative or summative programs was a key factor influencing teaching development. Formative programs were more likely to be embraced by participants as development opportunities. Where program participation was punitive or compliance driven due to a requirement to meet performance measures, participants typically experienced lower motivation to participate, and authors reported low program engagement (Atkinson \& Bolt, 2010; Bell, 2001; Bell \& Cooper, 2013; Cresswell et al., 2015). This may be a contributing factor to participant perceptions of limited benefits and anxiety related to concerns about failure (Bell \& Mladenovic, 2008; Bennett et al., 2012; Georgiou et al., 2018), a point raised by several other researchers (Hammersley-Fletcher \& Orsmond, 2005; Lomas \& Nicholls, 2005; Martsolf et al., 1998). Grainger et al. (2015) reported participation may be more likely in a summative model where it is linked to an official recognition of professional development or qualification. Otherwise, summative models tended to discourage intrinsic motivation and supported perceptions of PRT as an inspectorial model.

Several authors reported the positive role of peer observation and formative feedback at the program level (Atkinson \& Bolt, 2010; Bell, 2001; Bell \& Cooper, 2013; Bell \& Mladenovic, 2008; Georgiou et al., 2018; O’Keefe et al., 2009). However, differing assessments of the efficacy of observational partnering according to levels of academic experience were reported. Early career academics' experience of receiving feedback from an expert reviewer was reported as highly valuable (Bell, 2001; Bell \& Cooper, 2013; Bell 
\& Mladenovic, 2008; Bennett et al., 2012; Georgiou et al., 2018; Wright \& Main, 2015). Conversely, early career PRT partnerships reported short and long term benefits including confidence in teaching pedagogy, engagement with teaching scholarship literature, collegiality and personal development (Barnard et al., 2011; Woodman \& Parappilly, 2015). These benefits arose despite the potential limitations of pairing inexperienced staff, which is questioned in the broader literature (Kohut et al., 2007).

Disagreement over the benefits of feedback and observation is evidenced within the wider literature. Authors discussed participants' experience of vulnerability due to feeling judged while being observed (Hendry \& Oliver, 2012). Conversely, authors evidenced participant agency in the act of observing, through assessing colleagues based on their own judgement and observations of student responses. Engagement in critical dialogue within observational partnerships promoted reflection through a critical lens. In this way, PRT provided a context for growth in teaching knowledge and skills (Trigwell et al., 2000).

Inclusion of training components within program design was a factor that contributed to teaching development in some studies (Bell \& Cooper, 2013; Georgiou et al., 2018), however it was not always clear in articles whether these programs were optional or mandated. Within the broader literature, several authors similarly discuss the absence of reporting on whether training is mandated or even provided (Hammersley-Fletcher \& Orsmond, 2004; Lomas \& Nicholls, 2005; Shortland, 2004). Influence of training on teaching development is difficult to assess as it may have been underreported in the program description. Additionally, there was a lack of reporting on the extent of training in terms of time, financial and personnel resources.

A key factor that influenced teaching development at the individual level was participants' perceptions of program benefits. Authors reported contradictory findings on those most likely to benefit, which is also reflected in the wider literature. Some studies report teaching academics with moderate experience levels were well placed to benefit from PRT, as their level of experience afforded increased openness to pedagogical development and challenge when compared with their early career colleagues (White et al., 2013). Conversely, within medicine faculties, early career medical educators indicated they were more likely to benefit from engaging in PRT compared with more experienced colleagues (Caygill et al., 2017). This highlights that academics of various career stages can have different professional development requirements.

\section{Key considerations in designing an effective PRT program}

The overall message across studies in the review was that there is no one-size-fits-all program. Organisational leaders need to adapt the program according to factors at the organisational, program and individual levels. There are, however, some factors that contribute to the success of PRT programs and teaching development outcomes, and each of these potentially key factors require consideration when adapting a program.

At the organisational level, these factors include disciplinary-context specific needs, highly collegiate cultures and communicative, transparent leadership. Factors at the program level are formative models that include voluntary, flexible participation and training components to develop skills related to observation, feedback and reflective practice. Factors at the individual level include levels of teaching experience and 
perceptions of program benefit according to participant needs. Due to incomplete reporting, some programs may have had more key factors than reported.

\section{Limitations}

There are several limitations to this study. First, authors used varying degrees of specificity when reporting on study results. Of the 35 full-text articles assessed for eligibility, $40 \%$ of these were excluded on the bases of inadequate reporting of research design and methods of analysis.

Second, variation was found in authors' definitions and use of key concepts and lack of detailed descriptions of programs prevented adequate analysis of what programs work in what circumstances. Most authors discussed changes in attitudes, knowledge, skills and behaviours according to self-reported assessment. Due to limitations in self-reported assessment, further mixed-method studies could include validated scales, as only $21 \%$ of the studies reviewed used some form of validated tool to assess teaching development. Definitions of knowledge, skills and attitudes cannot be assumed to be homogeneous across studies, as definitions may be operationalised differently. This highlights issues of heterogeneity in program design and warrants further investigation, as programs may be executed differently than described, presenting issues with study fidelity (Bellg et al., 2004).

Third, while interactions between individual, program and organisational factors may be present within the reviewed articles, this was outside the review scope and not included. Future research could investigate how an individual's perceived development needs influence their engagement in PRT, which may have implications for program design and teaching development outcomes. Despite these limitations, this study provides an insight into PRT factors influencing academic teaching development in HE.

\section{Conclusion}

This systematic review aimed to further our understanding of PRT characteristics considered most effective for promoting teaching development in Australian HE. Due to variation in terminology used in the literature, development of a shared language to describe PRT will be useful in discussing future PRT-related practice. Overall, findings suggest there is no one-size-fits-all program. Outcomes are dependent on context specific models sensitively led according to participant needs.

Future program development could benefit from resource investment at the organisational level, including communicative leadership, PRT policy and administrative, financial and time provisions. At the program level, resources include training guidelines, collegial support, and models tailored to individual requirements. Inclusion of beneficial program activities include observation, feedback and critical reflection components. Content, duration and frequency of participant meetings also require consideration. At the individual level, opportunities for critical discourse, in addition to acknowledgement of participants' academic level, prior training and experience in teaching could be beneficial to engagement and overall program outcomes. In addition, our findings suggest improved reporting of program design and the development of valid and reliable 
tools to evaluate how PRT supports teaching development will add important insights for reporting on teaching quality outcomes.

As the first systematic analysis of literature on PRT related teaching development outcomes within the Australian higher education context, these findings contribute to advancing teaching scholarship and highlight the role of PRT in furthering our professional and scholarly obligation to teaching development.

\section{Disclosure statement}

No potential conflict of interest was reported by the author(s).

\section{ORCID}

Alexandra L. Johnston (D) http://orcid.org/0000-0002-9293-9298

Chi Baik (D) http://orcid.org/0000-0002-0480-5522

Andrea Chester (i) http://orcid.org/0000-0001-9245-0831

\section{References}

Alabi, J., \& Weare, W. (2014). Peer review of teaching: Best practices for a non-programmatic approach. Comminfolit, 8(2), 180. https://doi.org/10.15760/comminfolit.2014.8.2.171

Atkinson, D. J., \& Bolt, S. J. (2010). Using teaching observations to reflect upon and improve teaching practice in higher education. Journal of the Scholarship of Teaching and Learning, 10(3), 1-19.

Baik, C., \& Blasioli, J. (2018). Fostering teaching excellence at the University of Melbourne: The Melbourne peer review of teaching program.

Barnard, A., Croft, W., Irons, R., Cuffe, N., Bandara, W., \& Rowntree, P. (2011). Peer partnership to enhance scholarship of teaching: A case study. Higher Education Research \& Development, 30 (4), 435-448. https://doi.org/10.1080/07294360.2010.518953

Barnard, A., Nash, R., McEvoy, K., Shannon, S., Waters, C., Rochester, S., \& Bolt, S. (2015). LeaDIn: A cultural change model for peer review of teaching in higher education. Higher Education Research \& Development, 34(1), 30-44. https://doi.org/10.1080/07294360.2014.935931

Bell, M. (2001). Supported reflective practice: A programme of peer observation and feedback for academic teaching development. International Journal for Academic Development, 6(1), 29-39. https://doi.org/10.1080/13601440110033643

Bell, M., \& Cooper, P. (2013). Peer observation of teaching in university departments: A framework for implementation. International Journal for Academic Development, 18(1), 60-73. https://doi.org/10.1080/1360144x.2011.633753

Bell, M., \& Mladenovic, R. (2015). Situated learning, reflective practice and conceptual expansion: Effective peer observation for tutor development. Teaching in Higher Education, 20(1), 24-36. https://doi.org/10.1080/13562517.2014.945163

Bell, M., \& Mladenovic, R. (2008). The benefits of peer observation of teaching for tutor development. Higher Education, 55(6), 735-752. https://doi.org/10.1007/s10734-007-9093-1

Bell, M., \& Thomson, K. (2018). Supporting peer observation of teaching: Collegiality, conversations, and autonomy. Innovations in Education and Teaching International, 55(3), 276-284. https://doi.org/10.1080/14703297.2016.1212725

Bellg, A. J., Borrelli, B., Resnick, B., Hecht, J., Minicucci, D. S., Ory, M., Ogedegbe, G., Orwig, D., Ernst, D., \& Czajkowski, S. (2004). Enhancing treatment fidelity in health behavior change studies: Best practices and recommendations from the NIH behavior change consortium. Health Psychology, 23(5), 443-451. https://doi.org/10.1037/0278-6133.23.5.443 
Bennett, P. N., Parker, S., \& Smigiel, H. (2012). Paired peer review of university classroom teaching in a school of nursing and midwifery. Nurse Education Today, 32(6), 665-668. https://www. ncbi.nlm.nih.gov/pubmed/21835513 https://doi.org/10.1016/j.nedt.2011.07.005

Bowen, G. A. (2009). Document analysis as a qualitative research method. Qualitative Research Journal, 9(2), 27-40. https://doi.org/10.3316/QRJ0902027

Boyer, E. L. (1990). Scholarship reconsidered: Priorities of the professoriate. Princeton University Press.

Brown, B., \& Ward-Griffin, C. (1994). The use of peer evaluation in promoting nursing faculty teaching effectiveness: A review of the literature. Nurse Education Today, 14(4), 299-305. https://doi.org/10.1016/0260-6917(94)90141-4

Burrows, T, Findlay, N, Killen, C, Dempsey, S E, Hunter, S, Chiarelli, P, \& Snodgrass, S. (2011). Using nominal group technique to develop a consensus derived model for peer review of teaching across a multi-school faculty. Journal of University Teaching \& Learning Practice, 8(2), 1-9.

Carbone, A. (2011). Building peer assistance capacity in faculties to improve student satisfaction of units [Paper presentation]. HERDSA 2011: Higher Education on the Edge.

Carroll, C., \& O'Loughlin, D. (2014). Peer observation of teaching: Enhancing academic engagement for new participants. Innovations in Education and Teaching International, 51(4), 446456. https://doi.org/10.1080/14703297.2013.778067

Caygill, R., Peardon, M., Waite, C., McIntyre, I., Bradley, D., \& Wright, J. (2017). Attitudes towards peer review of teaching in medical education. Focus on Health Professional Education: A MultiDisciplinary Journal, 18(2), 47-60.

Chamberlain, J. M., D’Artrey, M., \& Rowe, D.-A. (2011). Peer observation of teaching: A decoupled process. Active Learning in Higher Education, 12(3), 189-201. https://doi.org/10. $1177 / 1469787411415083$

Chester, A. (2012). Peer partnerships in teaching: Evaluation of a voluntary model of professional development in tertiary education. Journal of the Scholarship of Teaching \& Learning, 12(2), 94108.

Cresswell, S. L., Gregory, S. J., \& Watters, D. J. (2015). The reluctance of scientists to engage in peer review of teaching. In C. Klopper \& S. Drew (Eds.), Teaching for learning and learning for teaching (pp. 227-245). Sense Publishers.

Creswell, J. W. (2002). Educational research: Planning, conducting, and evaluating quantitative and qualitative research. Merrill Prentice Hall.

Donnelly, R. (2007). Perceived impact of peer observation of teaching in higher education. International Journal of Teaching and Learning in Higher Education, 19(2), 117-129.

Georgiou, H., Sharma, M., \& Ling, A. (2018). Peer review of teaching: What features matter? A case study within STEM faculties. Innovations in Education and Teaching International, 55(2), 190200. https://doi.org/10.1080/14703297.2017.1342557

Gosling, D. (2002). Models of peer observation of teaching. Generic Centre: Learning and Teaching Support Network. University of East London.

Gosling, D. (2013). Collaborative peer-supported review of teaching. In J Sachs \& M Parsell (Eds.), Peer review of learning and teaching in higher education (p.13-31). Dordrecht: Springer

Gosling, D., \& O'Connor, K. M. (2006). From peer observation of teaching to review of professional practice (RPP): A model for continuing professional development (CPD). Educational Developments, 7(3), 1.

Grainger, P., Bridgstock, M., Houston, T., \& Drew, S. (2015). Working in triads: A case study of a peer review process. Journal of University Teaching \& Learning Practice, 12(1), 3.

Hammersley-Fletcher, L., \& Orsmond, P. (2004). Evaluating our peers: Is peer observation a meaningful process? Studies in Higher Education, 29(4), 489-503. https://doi.org/10.1080/ 0307507042000236380

Hammersley-Fletcher, L., \& Orsmond, P. (2005). Reflecting on reflective practices within peer observation. Studies in Higher Education, 30(2), 213-224. https://doi.org/10.1080/03075070500043358

Harris, K. L., Farrell, K., Bell, M., Devlin, M., \& James, R. (2008). Peer review of teaching in Australian higher education: A handbook to support institutions in developing and embedding effective policies and practices. Australian Learning and Teaching Council. 
Hendry, G. D., \& Oliver, G. R. (2012). Seeing is believing: The benefits of peer observation. Journal of University Teaching \& Learning Practice, 9(1), 7.

Kell, C., \& Annetts, S. (2009). Peer review of teaching embedded practice or policy-holding complacency? Innovations in Education and Teaching International, 46(1), 61-70. https://doi.org/ $10.1080 / 14703290802646156$

Klopper, C., \& Drew, S. (2015). Using most significant change to evaluate impact of the pro-teaching project. In C. Klopper \& S. Drew (Eds.), Teaching for learning and learning for teaching (pp. 247-259). Sense.

Klopper, C., Drew, S., \& Power, B. (2015). Enhancing learning by enhancing teaching: Peer assisted review and observation for course and teaching quality improvement. In C. Klopper \& S. Drew (Eds.), Teaching for learning and learning for teaching (pp. 53-62). Sense.

Kohut, G. F., Burnap, C., \& Yon, M. G. (2007). Peer observation of teaching. Perceptions of the observer and the observed. College Teaching, 55(1), 19-25. https://doi.org/10.3200/CTCH.55. $1.19-25$

Lomas, L, \& Kinchin, I. (2006). Developing a peer observation program with university teachers. International Journal of Teaching and Learning in Higher Education, 18(3), 204-214.

Lomas, L., \& Nicholls, G. (2005). Enhancing teaching quality through peer review of teaching. Quality in Higher Education, 11(2), 137-149. https://doi.org/10.1080/13538320500175118

Marchant, J., González, C., \& Fauré, J. (2018). The impact of a university teaching development programme on student approaches to studying and learning experience: Evidence from Chile. Assessment \& Evaluation in Higher Education, 43(5), 697-709. https://doi.org/10.1080/ 02602938.2017.1401041

Martin, G. A., \& Double, J. M. (1998). Developing higher education teaching skills through peer observation and collaborative reflection. Innovations in Education and Training International, 35(2), 161-170. https://doi.org/10.1080/1355800980350210

Martsolf, D., Dieckman, B., \& Heiss, M. (1998). Cultural factors related to the peer review of teaching. NursingConnections, 11(3), 41-54.

McMahon, T., Barrett, T., \& O’Neill, G. (2007). Using observation of teaching to improve quality: Finding your way through the muddle of competing conceptions, confusion of practice and mutually exclusive intentions. Teaching in Higher Education, 12(4), 499-511. https://doi.org/ 10.1080/13562510701415607

Nash, R. E., Barnard, A., Bolt, S., Shannon, S., McEvoy, K., Rochester, S., ... Waters, C. (2014). Developing a culture of peer review of teaching through a distributive leadership approach.

O’Keefe, M., Lecouteur, A., Miller, J., \& McGowan, U. (2009). The colleague development program: A multidisciplinary program of peer observation partnerships. Medical Teacher, 31 (12), 1060-1065. https://www.ncbi.nlm.nih.gov/pubmed/19995168 https://doi.org/10.3109/ 01421590903154424

Quinlan, K. M., \& Akerlind, G. S. (2000). Factors affecting departmental peer collaboration for faculty development: Two cases in context. Higher Education, 40(1), 23-52. https://doi.org/ 10.1023/a:1004096306094

Servilio, K., Hollingshead, A., \& Hott, B. (2017). Partnerships enhancing practice. Journal of Special Education Technology, 32(1), 23-35. https://doi.org/10.1177/0162643416681161

Shortland, S. (2004). Peer observation: A tool for staff development or compliance? Journal of Further and Higher Education, 28(2), 219-228. https://doi.org/10.1080/0309877042000206778

Shortland, S. (2010). Feedback within peer observation: Continuing professional development and unexpected consequences. Innovations in Education and Teaching International, 47(3), 295304. https://doi.org/10.1080/14703297.2010.498181

Suri, H, \& Clarke, D. (2009). Advancements in research synthesis methods: From a methodologically inclusive perspective. Review of Educational Research, 79(1), 395-430.

Thomas, J., Harden, A., \& Newman, M. (2012). Synthesis: Combining results systematically and appropriately. Sage Publications.

Trigwell, K., Martin, E., Benjamin, J., \& Prosser, M. (2000). Scholarship of teaching: A model. Higher Education Research \& Development, 19(2), 155-168. https://doi.org/10.1080/ 072943600445628 
Venema, S., Drew, S., \& Lodge, J. M. (2015). Peer observation as a collaborative vehicle for innovation in incorporating educational technology into teaching: A case study. In C. Klopper \& S. Drew (Eds.), Teaching for learning and learning for teaching (pp. 209-225). Sense.

Viskovic, A. (2006). Becoming a tertiary teacher: Learning in communities of practice. Higher Education Research \& Development, 25(4), 323-339. https://doi.org/10.1080/07294360 600947285

White, K., Boehm, E., \& Chester, A. (2013). Predicting academics' willingness to participate in peer review of teaching: A quantitative investigation. Higher Education Research \& Development, 33 (2), 372-385. https://doi.org/10.1080/07294360.2013.832162

Wingrove, D., Clarke, A., \& Chester, A. (2015). Distributing leadership for sustainable peer feedback on tertiary teaching. Journal of University Teaching \& Learning Practice, 12(3), 8.

Wingrove, D., Hammersley-Fletcher, L., Clarke, A., \& Chester, A. (2017). Leading developmental peer observation of teaching in higher education: Perspectives from Australia and England. British Journal of Educational Studies, 66(3), 365-381. https://doi.org/10.1080/00071005.2017. 1336201

Woodman, R. J., \& Parappilly, M. B. (2015). The effectiveness of peer review of teaching when performed between early-career academics. Journal of University Teaching \& Learning Practice, 12 (1), 2.

Wright, O., \& Main, K. (2015). Analysing peer pedagogic practices as a positive contribution to academic professional development. In C. Klopper \& S. Drew (Eds.), Teaching for learning and learning for teaching (pp. 117-133). Sense.

Yurtseven, N., \& Altun, S. (2018). The role of self-reflection and peer review in curriculum-focused professional development for teachers. Hacettepe University Journal of Education, 33(1), 207228. https://doi.org/10.16986/huje.2017030461 


\section{University Library}

\section{- M M I N E R VA A gateway to Melbourne's research publications}

Minerva Access is the Institutional Repository of The University of Melbourne

\section{Author/s:}

Johnston, AL;Baik, C;Chester, A

Title:

Peer review of teaching in Australian higher education: a systematic review

Date:

2020-11-19

Citation:

Johnston, A. L., Baik, C. \& Chester, A. (2020). Peer review of teaching in Australian higher education: a systematic review. HIGHER EDUCATION RESEARCH \& DEVELOPMENT, 41 (2), pp.390-404. https://doi.org/10.1080/07294360.2020.1845124.

Persistent Link:

http://hdl.handle.net/11343/274376 